\title{
Influences of diet and the gut microbiome on epigenetic modulation in cancer and other diseases
}

\author{
Bidisha Paul ${ }^{1}$, Stephen Barnes ${ }^{2,6,8}$, Wendy Demark-Wahnefried ${ }^{3,6,7,8}$, Casey Morrow ${ }^{4,6}$, Carolina Salvador ${ }^{5,7}$, \\ Christine Skibola ${ }^{6,10}$ and Trygve O. Tollefsbol $1,6,7,8,9^{*}$
}

\begin{abstract}
Epigenetic modulation of gene activity occurs in response to non-genetic factors such as body weight status, physical activity, dietary factors, and environmental toxins. In addition, each of these factors is thought to affect and be affected by the gut microbiome. A primary mechanism that links these various factors together in mediating control of gene expression is the production of metabolites that serve as critical cofactors and allosteric regulators of epigenetic processes. Here, we review the involvement of the gut microbiota and its interactions with dietary factors, many of which have known cellular bioactivity, focusing on particular epigenetic processes affected and the influence they have on human health and disease, particularly cancer and response to treatment. Advances in DNA sequencing have expanded the capacity for studying the microbiome. Combining this with rapidly improving techniques to measure the metabolome provides opportunities to understand complex relationships that may underlie the development and progression of cancer as well as treatment-related sequelae. Given broad reaching and fundamental biology, both at the cellular and organismal levels, we propose that interactive research programs, which utilize a wide range of mutually informative experimental model systems-each one optimally suited for answering particular questions - provide the best path forward for breaking ground on new knowledge and ultimately understanding the epigenetic significance of the gut microbiome and its response to dietary factors in cancer prevention and therapy.
\end{abstract}

Keywords: Epigenetics, Epigenome, Methylation, Acetylation, Histone proteins, Gut microbiome

\section{Background}

There is intense ongoing research activity to elucidate the relationship between the human microbiome and various diseases including cancer. "Microbiome" is a collective term used for the genes from colonizing organisms including fungi, viruses, and bacteria, the latter of which are by far the most populous. The microbiome are ubiquitous and distinct populations reside in the oral cavity, stomach, upper and lower intestine, urinary tract, genitalia, etc. It is increasingly believed to play a dynamic role in the health of

\footnotetext{
* Correspondence: trygve@uab.edu

'Department of Biology, University of Alabama at Birmingham, 175 Campbell Hall, 1300 University Boulevard, Birmingham, AL 35294-1170, USA

${ }^{6}$ Comprehensive Cancer Center, University of Alabama at Birmingham, Birmingham, AL, USA

Full list of author information is available at the end of the article
}

individuals. The gut is inhabited by the largest variety of bacteria, which contribute to the metabolism of different classes of food materials. An overwhelming 100 trillion commensal bacteria live within the human gastrointestinal tract, constantly exposing the surface of the intestinal mucosa to the stimulatory effects of this resident microbiota [86]. Humans are thought to have evolved a symbiotic relationship with the microbiota of the gut; however, the molecular mechanisms remain poorly understood. DNA-based analysis has significantly facilitated the identification of bacteria comprising the microbiome, but understanding function remains more challenging. For example, indigenous microbiota produce low molecular weight (LMW) substances that potentially interact with the tissue cellular environment to modulate signaling pathways and regulate gene expression. Recently, these LMW 
substances have been shown to influence epigenetic modifications, chromatin remodeling, and other signaling molecules, ultimately regulating apoptosis, cellular differentiation, and inflammation. Therefore, the epigenetic changes brought about by microbiota may contribute to prevention or therapeutic intervention of cancer or other diseases.

\section{Epigenetics}

The molecular mechanism of epigenetics involves many processes such as DNA methylation, posttranslational modification of histone proteins, silencing of the extra copy of the X-chromosome in females, and genomic imprinting. Non-coding RNAs including microRNA, small interfering RNA, and long non-coding RNA are also players that fall under the broader definition of epigenetics [51].

\section{DNA methylation}

DNA methylation is the addition of a methyl group to the carbon-5 position of the cytosine pyrimidine ring and occurs predominantly in cytosine guanine dinucleotiderich regions known as $\mathrm{CpG}$ islands that are found in the $5^{\prime}$ regulatory regions of most genes. The enzymes involved in DNA methylation are called DNA methyltransferases (DNMTs). TET (10-11 translocation) proteins are dioxygenase enzymes that hydroxylate 5-methylcytosine residues to form 5 -hydroxymethylcytosine $(5 \mathrm{hmC})$. They use a metabolite intermediate, $\alpha$-ketoglutarate $(\alpha-K G)$, and molecular oxygen as enzyme cofactors for this reaction [65]. Bacteria can cause changes in DNA methylation patterns of host cells by providing epigenetically active metabolites such as folate, butyrate, and acetate. These metabolites are essential for DNA methylation. For example, folate (produced by Bifidobacterium spp.) is a methyl donor and is necessary for generation of $S$-adenosylmethionine (SAM) which in turn is a methyldonating substrate for DNA methyltransferases [28]. The presence of $5 \mathrm{hmC}$ at bivalent loci and DNaseI hypersensitive sites (HS) might imply that simultaneous removal as well as renewed deposition of $5 \mathrm{mC}$ by DNMTs is taking place [55]. Thus, DNA methylation is a dynamic event and several cancers have been associated with this positional alteration of DNA methylation [29]. During carcinogenesis, epigenetic switching and 5-methylcytosine reprogramming result in the aberrant hypermethylation of $\mathrm{CpG}$ islands, leading to the unresponsiveness of tumor suppressor genes [85]. In cancers with a stem cell origin, isocitrate dehydrogenase (IDH) mutations result in the production of oncometabolite 2-hydroxyglutarate (2HG), leading to global hypermethylation, whereas in tumors with non-stem cell origin an intact metabolic function of IDH would be necessary to maintain DNA methylation plasticity [58] (Fig. 1).

\section{Chromatin remodeling and histone modification}

Histone acetylation is catalyzed by lysine acetyltransferases (KATs), which transfer an acetyl group from acetyl coenzyme A (acetyl-CoA) to lysine residues $(\mathrm{N} \varepsilon)$, with the concomitant production of CoA [73]. Acetylation is primarily associated with transcriptional activation, and most of the acetylation sites occur within the $\mathrm{N}$-terminal tail of the histones. Acetylation of the histones leads to increased accessibility of nucleosomal DNA to transcription factors. Histone deacetylases (HDACs) are opposite in function to histone acetyltransferases (HATs) as they remove the acetyl (acyl) moiety from lysine residues. Histone acetylation is regulated via the tricarboxylic acid (TCA) cycle. The gut microbiome produces short-chain fatty acids that are used to generate ATP via the TCA cycle. HDACs can also be inhibited by metabolites produced by the gut microbiome such as butyrate and propionate. ATP citrate lyase (ACL) uses mitochondrialderived citrate to generate acetyl-CoA in the cytoplasm and nucleus. In the nucleus, HATs transfer the acetyl group from acetyl-CoA onto histone lysine [77]. Histone methylation is also an important epigenetic process in that methylation of histones is effective in recruiting certain transcription factors to the chromatin. Lysine and arginine residues can be methylated histone methyltransferases. There are additional histone tail modifications such as histone phosphorylation, ubiquitination, sumoylation, histone poly-ADP ribosylation, histone biotinylation, citrullination, and proline isomerization. Moreover, there is cross-talk not only among the various histone modifications but also between DNA methylation and histone modification that often collectively work in tandem to control gene activity [40]. As for DNA, methylated histones undergo demethylation by the JmjC family of dioxygenases that once again depend on molecular oxygen and $\alpha-K G$.

\section{Non-coding RNA}

RNA that does not code for a protein is termed noncoding RNA (ncRNA). It is important to note that, unlike eukaryotes, ncRNAs form a small part of the prokaryotic genome although small ncRNA has been reported in bacteria. By contrast, the majority of the eukaryotic genome is transcribed into ncRNA which plays a major role in the regulation of messenger RNA (mRNA) translation. ncRNA can be divided into small and large ncRNAs. Small ncRNAs, also known as microRNAs (miRNAs), are approximately 18-20 nucleotides in length and play a critical role in gene regulation [38]. Small interfering RNAs (siRNAs) or PIWI-interacting RNAs (piRNAs) are key small ncRNAs that play important roles in several biological processes, especially cancer [18]. Long ncRNAs are 200 nucleotides in length or longer. The broad functional repertoire of long ncRNAs 
includes roles in high-order chromosomal dynamics, telomere biology, and subcellular structural organization [59]. Exosomes are nanovesicles (30-90 nm in diameter) secreted by intestinal epithelial cells (IECs) either from their apical or basolateral side [83]. Through the exosomes, proteins, lipids, mRNAs, and miRNAs are released. Exosomes carry molecules involved in adhesion and antigen presentation, comprising major histocompatibility complex (MHC) class I and class II molecules, tetraspan proteins, CD26/dipeptidyl-peptidase IV, and A33 antigen, a molecule essentially restricted to the intestinal epithelium [31, 52]. Apical secretion of exosomes into the lumen have an effect on the function of distant cells, whereas basolaterally released exosomes regulate local innate responses [24].

\section{Epigenetic influence through metabolite production by the gut microbiome}

The microbiota of the gastrointestinal tract harbors a huge collection of beneficial symbionts that aid in digestion, as well as provide a source of various nutrients. In most mammals, the gut is dominated by four bacterial phyla that perform these tasks: Firmicutes, Bacteroidetes, Actinobacteria, and Proteobacteria [45]. These microorganisms produce a number of LMW bioactive substances such as folate, butyrate, biotin, and acetate that may participate in epigenetic processes [36].

Folate is a vitamin that accepts one-carbon units from donor molecules and is involved in many metabolic pathways, such as methyl group biogenesis and synthesis of nucleotides, vitamins, and some amino acids [69]. The efficiency of DNA replication, repair, and methylation are affected by folate availability; rapidly proliferating cells such as leukocytes, erythrocytes, and enterocytes require large amounts of folate. Folate is widely distributed in the biological world, intestinal bacteria being one source of this vitamin [30].

Butyrate is a short-chain fatty acid (SCFA) and a potent inhibitor of HDACs [12]. The most important butyrate producer is Faecalibacterium prausnitzii which belongs to the cluster of Firmicute bacteria, comprised of Clostridium leptum, Eubacterium rectale, and Clostridium coccoides [49]. Butyrate has the ability to activate epigenetically silenced genes in cancer cells such as $p 21$ and $B A K$ [6]. Butyrate has been shown to repress angiogenesis in vitro and in vivo and reduces the expression of pro-angiogenic factors such as EGF and HIF $1 \alpha$ [99]. Increasing the concentration of butyrate in the colon can play a protective role and prevent cancer, and its production is dependent on diet and intestinal microflora composition. Butyrate is able to modulate intestinal microflora through regulation of $\mathrm{pH}$ and exerts many beneficial effects on the intestinal lumen through epigenetic mechanisms [94]. The HDAC inhibitor sodium butyrate is known to increase cell death in human medulloblastoma cells [62]. We have shown that epigallocatechin (EGCG) obtained from green tea and sodium butyrate given at physiological doses achievable in the human diet induced apoptosis and cell cycle arrest. They were found to be regulated by decreases in the epigenetic-modifying enzymes HDAC1 and DNMT1 as well as survivin in colon cancer cells [75].

Biotin is a vitamin that mammalian cells cannot produce, and they depend on a constant supply of biotin from the intestinal microbiota to maintain normal levels of protein biotinylation. Biotinylation is an important epigenetic process that involves the attachment of biotin to histone proteins resulting in gene repression, and it also plays a role in DNA repair and chromatin structure [79].

At the chromatin level, it has been widely demonstrated that the balance between acetylation and deacetylation of histone and non-histone proteins plays a pivotal role in the regulation of gene expression [67]. HATs and HDACs transfer an acetyl group from acetyl$\mathrm{CoA}$ to the $\mathcal{E}$-amino group of lysine and remove the acetyl group, respectively. CoA is a by-product in this reaction. The main donor of acetyl groups for formation of acetyl-CoA in acetylation reactions is the gut microbiota [78]. Similar to yeast, acetylation is regulated by metabolic intermediates of glucose, and one major enzyme involved is ATP citrate lyase, which converts citrate produced by the mitochondria into acetyl-CoA [19]. The ratio of acetyl-CoA to CoA is important for the regulation of acetylation in response to metabolic changes [1]. Under conditions of glucose deprivation, the ratio of acetyl-CoA to CoA drops, and this in turn affects histone acetylation levels. Studies in yeast have elucidated that high acetyl-CoA stimulates promoter histone acetylation [5]. This may have important implications in cancer studies as oncogenes may make use of acetyl-CoA metabolism to alter chromatin for growth [8].

The gut microbiota also contribute to the absorption and excretion of minerals such as zinc, iodine, selenium, cobalt, and others that are cofactors of enzymes participating in epigenetic processes. Moreover, various enzymes such as the methyltransferases, acetyltransferases, deacetylases, Bir A ligase, phosphotransferases, kinases, and synthetases are derived from the gut microbiota. A number of key energy metabolites including $S$-adenosylmethionine (SAM), acetyl-CoA, $\mathrm{NAD}^{+}, \alpha-\mathrm{KG}$, and ATP serve as essential cofactors for many, perhaps most, epigenetic enzymes that regulate DNA methylation, posttranslational histone modifications, and nucleosome position. Significant contributors in the epigenomic machinery are formed during energy metabolism in eukaryotic cell mitochondria and in the prokaryotic cell membrane signifying that any disorder in these processes 


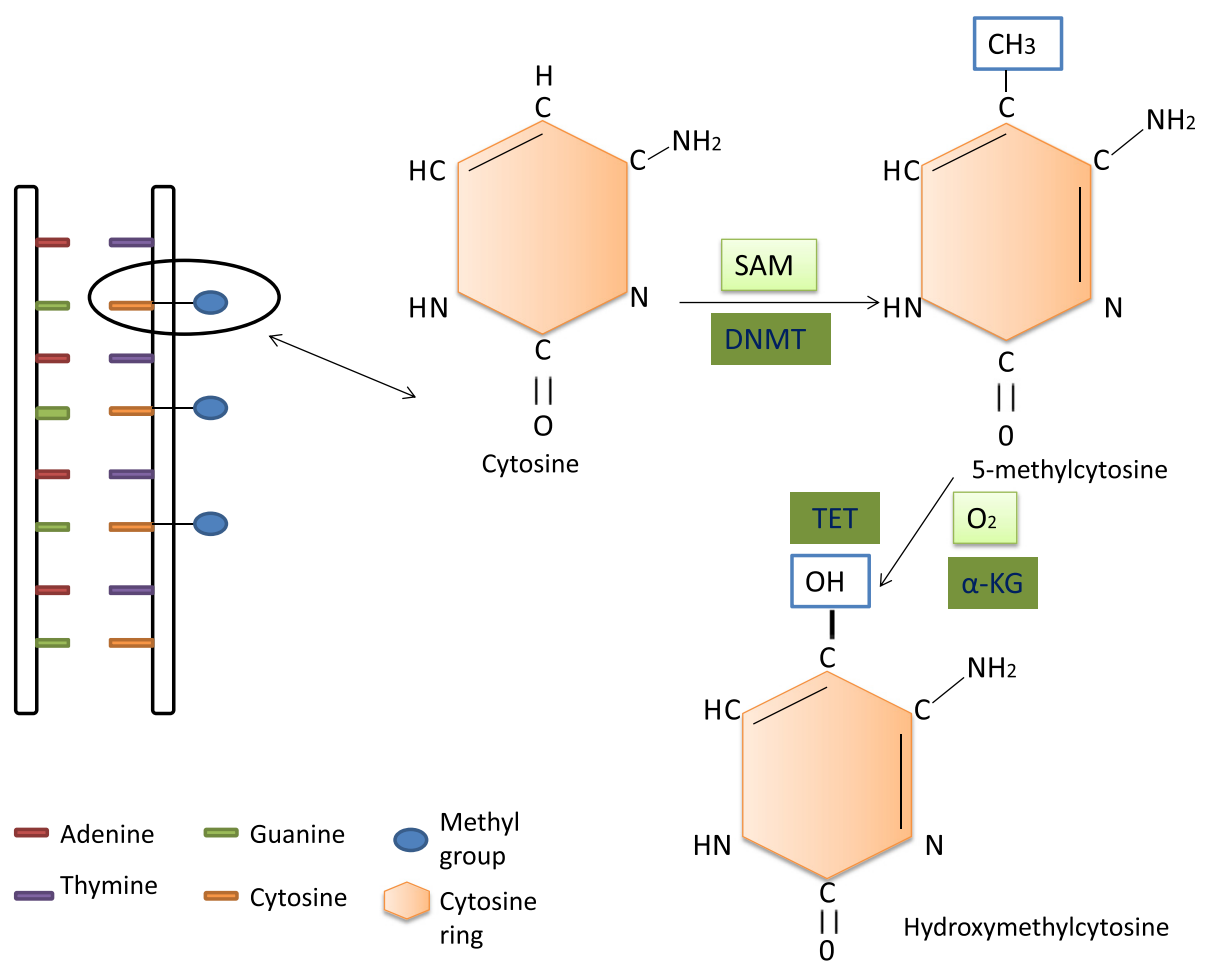

Fig. 1 The basic process of DNA methylation. S-adenosylmethionine (SAM) is used as the methyl ( $\mathrm{CH} 3)$ donor by the enzyme DNA methyltransferase (DNMT) to transfer a methyl group to cytosine rings of the DNA strands. TET proteins are dioxygenase enzymes that hydroxylate 5-methylcytosine residues to form 5 -hydroxymethylcytosine ( $5 \mathrm{hmC}$ ). They use a metabolite intermediate, a-ketoglutarate ( $a$ - $K G$ ), and molecular oxygen as enzyme cofactors for this reaction

can lead to a wide variety of diseases associated with epigenetic modifications [80] (Fig. 2).

\section{Food, the gut microbiota, and epigenetics}

It has been shown that maternal and neonatal nutrition have a major impact on the epigenome of the offspring in that the food consumed modulates the composition of the gut microbiota and also the metabolites that they produce [89]. The gastrointestinal tract of the fetus is virtually sterile; colonization begins at birth from the maternal microbiota of the genital tract, colon, and the overall environment [20]. The bacteria identified include members of the genera Bifidobacterium, Ruminococcus, Enterococcus, Clostridium, and Enterobacter. The composition of the gut microbiota is profoundly influenced by the diet of the infant [66]. In breast-fed infants, the microbiota predominantly consists of Bifidobacteria, and a plethora of diverse microbiota develops after the introduction of solid food commences. In contrast, the intestines of formula-fed infants are colonized by members of a variety of bacterial genera, including those of the enterobacterial genera Streptococcus, Bacteroides, and Clostridium, as well as members of the genus Bifidobacterium [20]. By the age of 2 years, the bacterial population of the gut is established and remains relatively constant throughout life, though disease processes, surgical interventions, medical therapies, and epigenetic-modulating factors such as the diet can influence the gut microbiome. Recent studies have revealed an association between bacterial predominance and epigenetic profile. A study on pregnant women with Firmicutes and Bacteroidetes as the dominant groups in their gut revealed a correlation between differential methylation status of gene promoters associated with obesity and cardiovascular disease [42].

The genetic content of an individual's gut microbial community is dynamic. It has also been observed that the incidence of colon cancer is lower in Asian countries where the diet consists of fruits and vegetables [20]. Microbiota within the colon convert dietary fiber into SCFAs by the process of fermentation, and as discussed previously, one of the predominant SCFAs is butyrate. Butyrate is naturally produced in the colon through microbial fermentation. It can induce cell differentiation [2], apoptosis [25], and histone hyperacetylation [7]; thus, it has potential to be a major chemotherapeutic agent.

High dietary consumption of fat and red meat (especially processed meat) is associated with increased risk of colorectal cancer. This effect is thought to be modulated by $N$-nitroso compounds and heterocyclic aromatic 


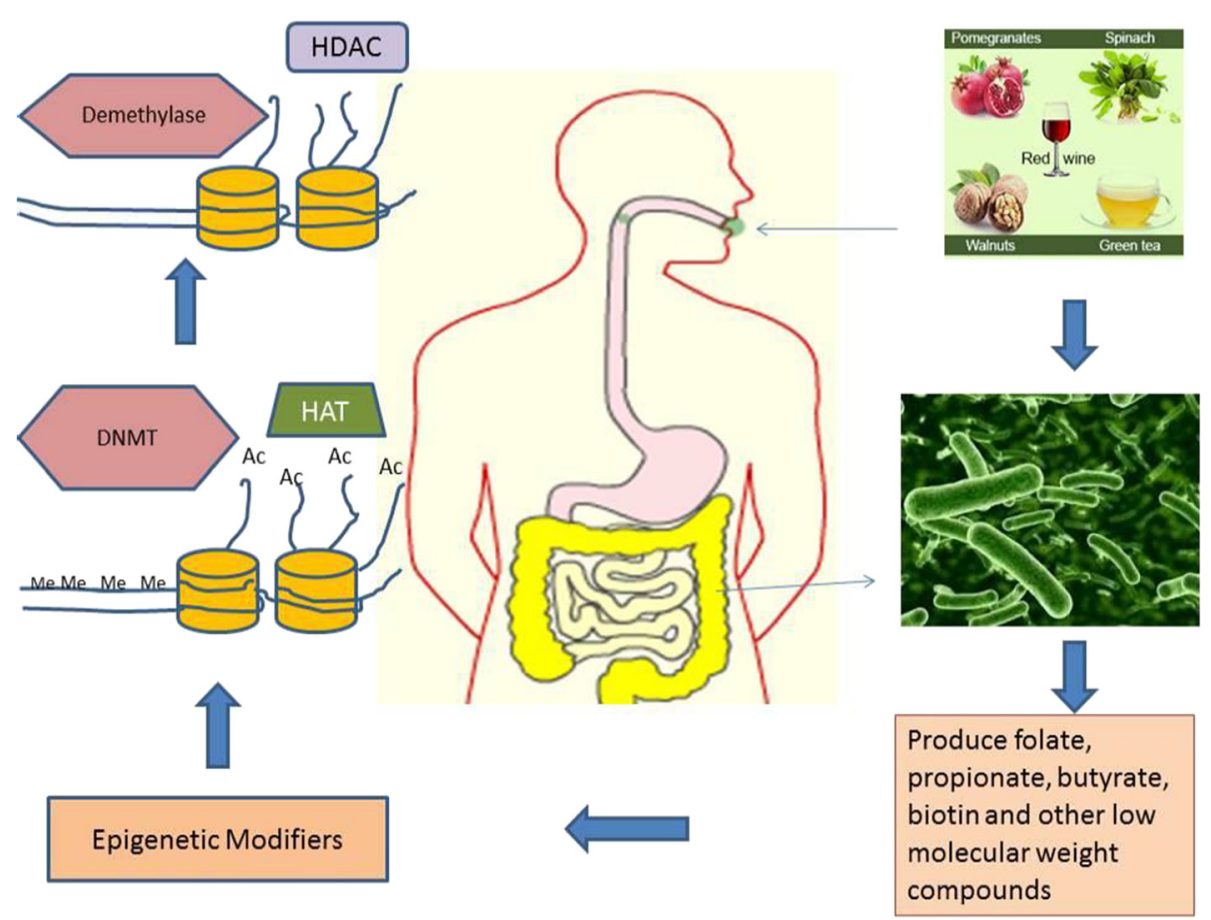

Fig. 2 The molecular interaction of the gut microbiota is greatly influenced by the dietary compounds consumed. The microbes residing in the human gut produce a number of low molecular weight molecules such as butyrate, folate, propionate, and biotin. These compounds either directly bring about epigenetic modifications such as changes in DNA methylation and histone acetylation or indirectly act via activation or inhibition of certain enzymes such as DNMTs, HDACs, or even hTERTs. Me DNA methylation, Ac histone acetylation

amines [33]. Consumption of red meat delivers Lcarnitine to gut bacteria. These bacteria digest L-carnitine and convert it into trimethylamine- $N$-oxide (TMAO). In studies in mice, TMAO has been shown to cause atherosclerosis [39]. Cruciferous vegetables such as cabbage, broccoli, kale, and cauliflower are rich sources of fiber, lutein, flavonoids, phytosterols, folic acid, sulfur-containing glucosinolates, and vitamin $\mathrm{C}$, each of which has been associated with reduced risk of various kinds of cancer [27]. Moreover, sulfur-containing glucosinolates can be converted to biologically active compounds such as indoles, nitriles, and isothiocyanates (ITCs) by $\beta$-thioglucosidases produced by the gut microbiome [61]. The glucosinolate of sulforaphane (SFN) is contained in several cruciferous vegetables but is present in highest concentration in broccoli [97]. ITCs can also exert epigenetic effects via modulation of DNA methylation. For example, DNA methyltransferases are downregulated by SFN, which can lead to site-specific CpG island demethylation in the telomerase reverse transcriptase (TERT) gene and a reduction of its cancer-sustaining expression [57].

\section{Cancer and the gut microbiome}

\section{Gastric cancer}

Gastric cancers are often caused by infection with Helicobacter pylori which induces chronic gastritis and peptic ulcers [100]. Virulent strains harbor cytotoxinassociated gene pathogenicity island (CagPAI) that encode components of type IV secretion system (T4SS) [13]. Cag A oncoproteins are transported across the host cell membrane via the type IV secretion system T4SS. Studies have shown that $H$. pylori CagPAI dependently induces dephosphorylation of histone H3S10, H3 threonine 3, and deacetylation of H3K23 in gastric epithelial cells but does not affect nine other distinct histone modifications [14]. Microbial pathogens often manipulate host cell mechanisms through histone modifications. Hence, targeting these epigenetic modifications may be one of the important therapeutic strategies to stop the infection. Dietary phytochemicals with HDAC- or HATinhibiting properties may play a pivotal role in altering these histone modifications.

\section{Colon cancer}

Intestinal environmental changes are keys to progression toward adenoma and subsequently to colon cancer. A recent study has shown significant changes in fecal microbiota, especially decreases in fecal SCFA concentrations (acetate, propionate, and butyrate) and significant increases in fecal $\mathrm{pH}$ in colon cancer patients compared with healthy individuals [63]. It was also observed that the count of obligate anaerobes was 
significantly decreased in the case of colon cancer [56]. It has been hypothesized that it may be possible to prevent colorectal cancer by improving the intestinal environment, as the decrease in count of microbiota may be one of the causes of colon cancer development and progression. Adding probiotics to the diet is speculated as a way to reduce the risk of colon cancer [96]. In addition, adding cruciferous vegetables and green tea polyphenols may further bring about epigenetic modifications in the bacterial DNA or the genes that they target [34]. The microbiome may undergo significant changes in other forms of cancer such as breast cancer. It has often been observed that patients on chemotherapy have diarrhea and irritable bowel syndrome. Studies have shown considerable changes in the microbiome of the patients undergoing chemotherapy [84]. Therefore, improving the quality of the intestinal microbiota may be a therapeutic option to alleviate some of these side effects of chemotherapy and improve the quality of life of these patients. The alteration of the gut microbiome has been shown in several diseases including cancer as is summarized in Table 1.

A study of the stool microbiome and metabolome differences between colorectal cancer (CRC) and healthy adults showed that several butyrate-producing bacteria were underrepresented in CRC samples, whereas mucindegrading species Akkermansia muciniphila were about fourfold higher [95]. There is evidence to suggest that induction of pro-inflammatory responses by commensal bacteria contributes to tumor initiation and development [16]. Production of genotoxins and DNA-damaging superoxide radicals by Enterococcus faecalis are also mechanisms by which commensals can contribute to CRC development [23]. Irritable bowel syndrome including ulcerative colitis and Crohn's disease also predisposes to CRC [72]. A study showed that infection with Helicobacter hepaticus in Rag $2^{-1-}$ mice led to increased inflammation and elevated TNF- $\alpha$ production [17]. SCFAs such as butyrate, acetate, and propionate, which are fermentation products from dietary fibers by colonic gut microbiota, can regulate neutrophil function and migration and exhibit anti-inflammatory activity [15]. Butyrate can induce TNF- $\alpha$ to potentiate cell death [35] and can, via miRNA-dependent $p 21$ gene expression activity, lead to colon cancer prevention [32].

\section{Hormone-dependent, breast, ovarian, and endometrial cancer}

There is an increasing interest in other cancers that may have directly or indirectly been influenced by the gut microbiome. The gut microbiome modulates estrogen metabolism and contributes to the proportion of recirculated and excreted estrogen and estrogen metabolites [22]. The introduction of bacteria in germfree mice led to a significant rise in the reproductive capacity of the germfree mice [81]. The capacity of reproduction of germfree mice is generally lower. However, addition of bacteria showed normalization in the estrous cycle and a significant rise in copulation and implantation rates. Also, there were studies that showed that a reduction in the population of specific gut bacteria in humans causes increased fecal excretion of conjugated estrogens and decreases in urinary estrogens. Human fecal extracts metabolize plasma estrone (E1), 17 $\beta$-estradiol

Table 1 Alteration of gut microbiome in human diseases

\begin{tabular}{|c|c|c|}
\hline Disease & Microbiome alteration & Reference \\
\hline Irritable bowel syndrome & Increased ratio of the Firmicutes to Bacteroidetes & (Rajilić-Stojanović, Biagi et al. 2011) [70] \\
\hline Crohn's disease & $\begin{array}{l}\text { Increased Clostridium species, Ruminococcus torques, } \\
\text { and E. coli }\end{array}$ & (Martinez-Medina, Aldeguer et al. 2006) [53] \\
\hline Gastric cancer & $\begin{array}{l}\text { H. pylori induces production of pro-inflammatory } \\
\text { cytokines }\end{array}$ & (Tsuji, Kawai et al. 2003) [88] \\
\hline Colorectal cancer & Abundance of Fusobacteria and Coriobacteria & (Castellarin, Warren et al. 2012) [9] \\
\hline Obesity & Reduced ratio of Bacteroidetes to Firmicutes & (Ley, Bäckhed et al. 2005) [44] \\
\hline Type 1 diabetes & Altered gut permeability to mannitol and lactulose & (Kuitunen, Saukkonen et al. 2002) [41] \\
\hline Atherosclerosis & $\begin{array}{l}\text { Metabolism of phospholipids by gut microbiota to } \\
\text { trimethylamine- } N \text {-oxide }\end{array}$ & (Loscalzo 2011) [48] \\
\hline Rheumatoid arthritis & $\begin{array}{l}\text { Less Bifidobacteria and bacteria of the Bacteroides- } \\
\text { Porphyromonas-Prevotella }\end{array}$ & (Vaahtovuo, Munukka et al. 2008) [90] \\
\hline \multirow[t]{2}{*}{ Autism } & \multirow{2}{*}{$\begin{array}{l}\text { Higher number of Clostridium species known to } \\
\text { produce tetanus neurotoxin (TeNT) }\end{array}$} & (Parracho, Bingham et al. 2005) [64] \\
\hline & & (Bolte 1998) [4] \\
\hline Chronic fatigue syndrome & $\begin{array}{l}\text { Lower levels of Bifidobacteria and small-intestinal } \\
\text { bacterial overgrowth }\end{array}$ & (Logan, Venket Rao et al. 2003) [47] \\
\hline Alzheimer's disease & Excess ammonia production by gut microbiota & (Samsel and Seneff 2013) [76] \\
\hline
\end{tabular}




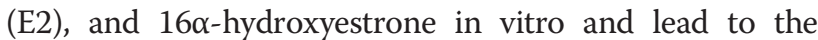
inter-conversion of E1 and E2 and the reduction of $16 \alpha$ hydroxyestrone to estriol (E3), 16-oxoestradiol to 16-

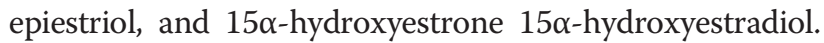
The human gut microbiome can influence the estrabolome. This is due to the presence of aggregate of enteric bacterial genes whose products are capable of metabolizing estrogen. Some bacterial species possess $\beta$-glucuronidases and $\beta$-glucuronides which are the enzymes involved in estrogen deconjugation and conjugation [68]. Deconjugation reactions may result in greater reabsorption of free estrogens, leading to the development of estrogen-driven cancers such as breast, ovarian, and endometrial cancers. Phase II hepatic conjugation reactions of E1 and E2 include methylation via catechol-O-methyltransferase (COMT) and glucuronidation via uridine $5^{\prime}$-diphospho-glucuronosyltransferase. COMT converts genotoxic catechol estrogens to their inactive methoxy derivatives, 2-MeOE2 and 4-MeOE2. Thus, consumption of certain plant-based diet (such as tomato) containing high levels of $O$-methyltransferases may reduce exposure to potentially mutagenic estrogen metabolites [50]. Daidzein is converted by gut microflora into dihydrodaidzein, S-(-)equol (70 \%) and $O$-desmethylangolensin (5-20\%) [37]. Studies on soy isoflavones have shown that the ability to produce equol varies (only 30-50 \% of US populations are equol producers) and is primarily dependent on intestinal bacterial composition of an individual $[3,43]$. It has been shown that the amount of urinary equol excretion is correlated with a reduced risk of breast cancer, and epigenetic modifications may play a role in impacting cancer secondary to changes in metabolites [74]. The study of these interactions may provide new avenues for therapeutic research. Colonization with specific bacteria that can modulate levels of certain metabolites may be another way to target diseases such as cancer.

\section{Liver cancer}

Toll-like receptors (TLR4) are activated by lipopolysaccharide (LPS) from gut bacteria and may contribute to injury and inflammation-driven tumor promotion in the liver [11]. Epigenetic regulation of TLR4 gene expression in intestinal epithelial cells can act as one mechanism for maintaining intestinal homeostasis by suppressing excessive responses to the commensals and regulating mucosal inflammation in the gut [87]. Dietary regulation of epigenetic modification may be useful for the prevention of liver cancer. SCFAs produced by gut microbiota bind G protein-coupled receptor 43 (GPCR43), and this interaction affects inflammatory responses [46]. GPR43deficient $\left(\mathrm{Gpr} \mathrm{3}^{-/-}\right)$mice showed exacerbated inflammation in models of colitis, arthritis, and asthma [92].
These effects appear to relate to increased production of inflammatory mediators by $\mathrm{Gpr}_{4} 3^{-/-}$immune cells and increased immune cell recruitment [93].

\section{Lung cancer}

Chronic inflammation plays a central role in the pathogenesis of chronic obstructive pulmonary disease (COPD) and lung tumorigenesis. Chromatin modifications and other epigenetic changes, angiogenesis, and apoptosis are crucial in the development of COPD and lung cancer [98]. Recent studies have established a role of miRNA as a pathogenic link between COPD and lung cancer [82]. Hence, emerging science should explore the relationship between the gut microbiome, its various metabolites, and cancer epigenetics (Table 2).

\section{Conclusion}

The indigenous microbiota plays a very important role in either directly or indirectly affecting epigenetic processes in the body. The LMW molecules produced by the microbiota of the gut participate in various molecular pathways and thus are implicated in the etiology of many diseases. Diet also plays a vital role in maintaining the health of an individual as the dietary components directly interact with the LMW molecules produced by the microbiota. Thus, studying the interrelationship between the human gut microbiota, their genetic makeup, the epigenome, and dietary components may offer new therapeutic options for treating diseases. Studies on family clusters of nonagenarian and centenarian siblings have shown that apart from inheriting exceptional gene groups, behavior and lifestyle have contributed to their aging well phenotype [71]. Thus, the study of this interrelation is important for disease prevention. The Human Microbiome Project aims at a better understanding of the roles of microbes on human biology including their relationship with health and disease [91]. The human intestinal microbiome will pave the way leading to a new frontier in human biology, in which the human genome and the bioactive products from the intestinal microbiome are tightly linked together as an integral part of the "human metagenome." Bioactive products such as LMW compounds may bring about epigenetic changes that directly and/or indirectly modify various epigenetic pathways through hormonal intermediates or immunological messengers. The study of epigenetic changes dependent on the microbiome is especially important for the study of cancer. A good animal model is essential for the study of the interactions among diet, gut microbiome, and cancer. The majority of anaerobic bacteria present in our digestive tract cannot be cultivated on existing media. Zebrafish can be a good model for microbiome studies as they share a great deal of homology with mammals. Most zebrafish genes have mammalian orthologs, and most epigenetic 
Table 2 Gut microbiota and its emerging science in cancer epigenetics

\begin{tabular}{|c|c|c|c|c|}
\hline Cancer & Link to gut microbiome & Link to epigenetics & Possible therapy & Reference \\
\hline \multirow[t]{3}{*}{ Gastric } & \multirow{3}{*}{$\begin{array}{l}\text { H. pylori causes gastric pathology } \\
\text { by injecting about } 128 \mathrm{kDa} \text { Cytotoxin- } \\
\text { associated gene } \mathrm{A}(\mathrm{Cag} \mathrm{A}) \text { protein } \\
\text { which enhanced c-Myc and } \\
\text { DNMT3B expression }\end{array}$} & \multirow{3}{*}{$\begin{array}{l}\text { H. pylori increased histone } \mathrm{H} 4 \\
\text { acetylation in the promoter } \\
\text { region of } p 21 \text { thereby increasing } \\
\text { p21 expression }\end{array}$} & \multirow{3}{*}{$\begin{array}{l}\text { Dietary compounds that have } \\
\text { HAT-inhibiting activities }\end{array}$} & (Hayashi, Tsujii et al. 2012) [26] \\
\hline & & & & (Ding, Goldberg et al. 2010) [13] \\
\hline & & & & (Fehri, Rechner et al. 2009) [21] \\
\hline \multirow[t]{2}{*}{ Colon } & \multirow[t]{2}{*}{$\begin{array}{l}\text { Elevated TNF-a expression in } \\
\text { the colon }\end{array}$} & \multirow{2}{*}{$\begin{array}{l}\text { TNF-a-suppressed differentiation } \\
\text { and potentiated cell death induced } \\
\text { by butyrate (NaBt) in both } \\
\text { adenocarcinoma HT-29 and fetal } \\
\text { FHC human colon cells in vitro }\end{array}$} & \multirow{2}{*}{$\begin{array}{l}\text { Sodium butyrate which is an } \\
\text { HDAC inhibitor can induce } \\
\text { TNF-a to potentiate cell death }\end{array}$} & $\begin{array}{l}\text { (Hýžd'alová, Hofmanova et al. } \\
\text { r2008) [35] }\end{array}$ \\
\hline & & & & (Erdman, Rao et al. 2009) [17] \\
\hline \multirow{2}{*}{$\begin{array}{l}\text { Estrogen-dependent } \\
\text { cancers }\end{array}$} & \multirow{2}{*}{$\begin{array}{l}\text { Bacterial species possess } \\
\beta \text {-glucuronidases and } \beta \text {-glucuronides } \\
\text { that participate in estrogen } \\
\text { conjugation and deconjugation }\end{array}$} & \multirow{2}{*}{$\begin{array}{l}\text { Phase II hepatic conjugation } \\
\text { reactions of E1 and E2 include } \\
\text { methylation via catechol-O- } \\
\text { methyltransferase, glucuronidation } \\
\text { via uridine } 5^{\prime} \text {-diphospho- } \\
\text { glucuronosyltransferase }\end{array}$} & \multirow{4}{*}{$\begin{array}{l}\text { Certain plant-based dietary } \\
\text { compounds contain } \\
\text { O-methyltransferase enzymes } \\
\text { that can inactivate catechol } \\
\text { estrogens }\end{array}$} & (Plottel and Blaser 2011) [68] \\
\hline & & & & (Mageroy, Tieman et al. 2012) [50] \\
\hline \multirow[t]{2}{*}{ Liver } & \multirow{2}{*}{$\begin{array}{l}\text { TLR4 activation by LPS from gut } \\
\text { bacteria contributes to tumor } \\
\text { promotion }\end{array}$} & \multirow[b]{2}{*}{$\begin{array}{l}\text { Epigenetic regulation of TLR4 } \\
\text { gene expression in intestinal } \\
\text { epithelial cells (IECS) can act as } \\
\text { one mechanism for maintaining } \\
\text { intestinal homeostasis by } \\
\text { suppressing excessive responses } \\
\text { to the commensals and } \\
\text { regulating mucosal inflammation } \\
\text { in the gut }\end{array}$} & & (Dapito, Mencin et al. 2012) [11] \\
\hline & & & & (Takahashi, Sugi et al. 2011) [87] \\
\hline Lung & $\begin{array}{l}\text { SCFAs produced by gut microbiota } \\
\text { bind GPCR } 43 \text { which affects } \\
\text { inflammatory responses. GPR43- } \\
\text { deficient }\left(G p r 43^{-/}\right) \text {mice showed } \\
\text { exacerbated or unresolving } \\
\text { inflammation in models of colitis, } \\
\text { arthritis, and asthma }\end{array}$ & $\begin{array}{l}\text { SCFAs are known to have HDAC- } \\
\text { inhibiting activities }\end{array}$ & $\begin{array}{l}\text { SCFAs are produced by } \\
\text { fermentation of } \\
\text { carbohydrates by gut } \\
\text { microbiota }\end{array}$ & (Maslowski, Vieira et al. 2009) [54] \\
\hline
\end{tabular}


regulators are highly conserved: there are 75 and $92 \%$ identity between zebrafish and human DNMT1 and $H D A C 1$, respectively [60]. Some other useful models for exploring host-microbiota interactions are fruit fly and yeast. However, most extensively used models for the study of cancer are rodents. Human fecal samples can be transplanted into rodents that are raised in a germfree environment where they have no exposure to microbes. Such animals, called gnotobiotic mice, are helpful in studying microbial community compositions by varying diet and disease parameters. These mice can harbor the microbial community in humans and hence are called "humanized mice." It is, however, important to note that although germfree mice do not harbor live bacteria, they still are exposed to a minimum amount of microbes in food, water, and bedding. They can be further induced with cancer cell line xenografts, and different dietary interventions can be introduced for effective study of intestinal microbial epigenetics [10]. Epigenetic dietary phytochemicals such as SFN from broccoli sprouts, EGCG from green tea, or genistein from soy products may positively enhance the interaction among metabolism, diet, gut microbiome, and epigenome. This can be very useful to treat a variety of cancers such as colon, lung, or even breast cancers where the current chemotherapy drugs such as doxorubicin/docetaxel can strip the body of its essential microbiome. Administering an "epigenetic diet" along with conventional treatment can be effective in enhancing the quality of the microbiome in cancer patients. Thus, by manipulating both the microbiome and the diet, we may discover novel therapies that act through epigenetic pathways and add to our armamentarium against cancer.

\begin{abstract}
Abbreviations
ASD: autism spectrum disorder; CagPAl: cytotoxin-associated gene pathogenicity island; COPD: chronic obstructive pulmonary disease; CRC: colorectal cancer; CREB: CAMP response element-binding protein; DNMT: DNA methyltransferase; EGCG: epigallocatechin; HAT: histone acetyltransferase; HDAC: histone deacetylase; HMP: Human Microbiome Project; HMT: histone methyltransferase; ITC: isothiocyanate; LMW: low molecular weight; MBD: methyl binding domain; MECP2: methyl CpG binding protein 2; piRNA: PIWI-interacting RNA; PPA: propionic acid; SCFA: short-chain fatty acid; SFN: sulforaphane; TLR: toll-like receptor; TMAO: trimethylamine-N-oxide; $\mathbf{a}-\mathrm{KG}$ : alpha ketoglutarate.
\end{abstract}

\section{Competing interests}

The authors declare that they have no competing interests.

\section{Authors' contributions}

$\Pi T$ and BP conceived of the review article and participated in all of the drafts of the manuscript. BP wrote the first draft of the manuscript with guidance from $T$. SB contributed to the metabolic aspects of the article and WD, CS, and CS contributed to the dietary aspects of writing of the manuscript. CM contributed to writing of the microbiome aspects of the article. $\Pi$ T provided the final editing of the manuscript. All authors read and approved the final draft.

\section{Acknowledgements}

This work was supported in part by a grant from the UAB Comprehensive Cancer Center to SB, WD, TT, C. Salvador, and C. Skibola and grants from the National Cancer Institute (R01 CA178441) and the American Institute for Cancer Research (316184) to TT.

\section{Author details}

'Department of Biology, University of Alabama at Birmingham, 175 Campbell Hall, 1300 University Boulevard, Birmingham, AL 35294-1170, USA. ${ }^{2}$ Department of Pharmacology and Toxicology, University of Alabama at Birmingham, Birmingham, AL, USA. ${ }^{3}$ Department of Nutrition Sciences, University of Alabama at Birmingham, Birmingham, AL, USA. ${ }^{4}$ Department of Cell, Developmental and Integrative Biology, University of Alabama at Birmingham, Birmingham, AL, USA. ${ }^{5}$ Division of Medical Oncology/ Hematology, University of Alabama at Birmingham, Birmingham, AL, USA. ${ }^{6}$ Comprehensive Cancer Center, University of Alabama at Birmingham, Birmingham, AL, USA. ${ }^{7}$ Comprehensive Center for Healthy Aging, University of Alabama at Birmingham, Birmingham, AL, USA. ${ }^{8}$ Nutrition Obesity Research Center, University of Alabama at Birmingham, Birmingham, AL, USA. ${ }^{9}$ Comprehensive Diabetes Center, University of Alabama at Birmingham, Birmingham, AL, USA. ${ }^{10}$ Department of Epidemiology, University of Alabama at Birmingham, Birmingham, AL, USA.

Received: 26 July 2015 Accepted: 22 September 2015

Published online: 16 October 2015

\section{References}

1. Albaugh BN, Arnold KM, Denu JM. KAT (ching) metabolism by the tail: insight into the links between lysine acetyltransferases and metabolism. Chembiochem. 2011;12(2):290-8.

2. Augeron C, Laboisse CL. Emergence of permanently differentiated cell clones in a human colonic cancer cell line in culture after treatment with sodium butyrate. Cancer Res. 1984;44(9):3961-9.

3. Barnes S, Prasain J, D'Alessandro T, Arabshahi A, Botting N, Lila MA. The metabolism and analysis of isoflavones and other dietary polyphenols in foods and biological systems. Food Function. 2011;2(5):235-44.

4. Bolte E. Autism and Clostridium tetani. Med Hypotheses. 1998;51(2):133-44.

5. Cai L, Sutter BM, Li B, Tu BP. Acetyl-CoA induces cell growth and proliferation by promoting the acetylation of histones at growth genes. Mol Cell. 2011;42(4):426-37.

6. Canani RB, Costanzo MD, Leone L. The epigenetic effects of butyrate: potential therapeutic implications for clinical practice. Clin Epigenetics. 2012;4(1):4.

7. Candido EPM, Reeves R, Davie JR. Sodium butyrate inhibits histone deacetylation in cultured cells. Get Cell. 1978;14(1):105-13.

8. Carrer A, Wellen KE. Metabolism and epigenetics: a link cancer cells exploit. Curr Opin Biotechnol. 2015;34:23-9.

9. Castellarin M, Warren RL, Freeman JD, Dreolini L, Krzywinski M, Strauss J. Fusobacterium nucleatum infection is prevalent in human colorectal carcinoma. Genome Res. 2012;22(2):299-306.

10. Cheon D-J, Orsulic S. Mouse models of cancer. Annual Review of Pathology: Mechanisms of Disease. 2011;6:95-119.

11. Dapito DH, Mencin A, Gwak GY, Pradere JP, Jang MK, Mederacke I. Promotion of hepatocellular carcinoma by the intestinal microbiota and TLR4. Cancer Cell. 2012;21(4):504-16.

12. Davie JR. Inhibition of histone deacetylase activity by butyrate. J Nutr. 2003;133(7):2485S-93.

13. Ding S-Z, Fischer W, Kaparakis-Liaskos M, Liechti G, Merrell DS, Grant PA. Helicobacter pylori- induced histone modification, associated gene expression in gastric epithelial cells, and its implication in pathogenesis. PLoS One. 2010;5(4), e9875.

14. Ding S-Z, Goldberg JB, Hatakeyama M. Helicobacter pylori infection, oncogenic pathways and epigenetic mechanisms in gastric carcinogenesis. Future Oncol. 2010;6(5):851-62.

15. Donohoe DR, Garge N, Zhang X, Sun W, O'Connell TM, Bunger MK. The microbiome and butyrate regulate energy metabolism and autophagy in the mammalian colon. Cell Metab. 2011;13(5):517-26.

16. Elinav E, Nowarski R, Thaiss CA, Hu B, Jin C, Flavell RA. Inflammation-induced cancer: crosstalk between tumours, immune cells and microorganisms. Nat Rev Cancer. 2013;13(11):759-71.

17. Erdman $S$, Rao VP, Poutahidis $T$, Rogers $A B$, Taylor $C L$, Jackson EA. Nitric oxide and TNF-a trigger colonic inflammation and carcinogenesis in Helicobacter hepaticus-infected, Rag2-deficient mice. Proc Natl Acad Sci. 2009;106(4):1027-32.

18. Esteller M. Non-coding RNAs in human disease. Nat Rev Genet. 2011;12(12):861-74. 
19. Evertts AG, Zee BM, DiMaggio PA, Gonzales-Cope M, Coller HA, Garcia BA. Quantitative dynamics of the link between cellular metabolism and histone acetylation. J Biol Chem. 2013;288(17):12142-51.

20. Favier CF, Vaughan EE, Vos WMD, Akkermans ADL. Molecular monitoring of succession of bacterial communities in human neonates. Appl Environ Microbiol. 2002;68(1):219-26.

21. Fehri LF, Rechner C, Ben SJ, Mak TM, Holland C, Bartfeld S. "Helicobacter pylori-induced modification of the histone $\mathrm{H} 3$ phosphorylation status in gastric epithelial cells reflects its impact on cell cycle regulation.". Epigenetics. 2009;4(8):577-86.

22. Fuhrman BJ, Feigelson HS, Flores R, Gail MH, Xu X, Ravel J. Associations of the fecal microbiome with urinary estrogens and estrogen metabolites in postmenopausal women. J Clin Endocrinol Metabol. 2014;99(12):46320-40.

23. Gao Z, Guo B, Gao R, Zhu Q, Qin H. Microbiota disbiosis is associated with colorectal cancer. Front Microbiol. 2015;6:20.

24. Gottesman S. Micros for microbes: non-coding regulatory RNAs in bacteria. TRENDS Genetics. 2005;21(7):399-404.

25. Hague A, Manning AM, Hanlon KA, Hart D, Paraskeva C, Huschtscha LI. Sodium butyrate induces apoptosis in human colonic tumour cell lines in a p53-independent pathway: implications for the possible role of dietary fibre in the prevention of large-bowel cancer. Int J Cancer. 1993;55(3):498-505.

26. Hayashi Y, Tsujii M, Jun W, Kondo J, Akasaka T, Jing Y. CagA mediates epigenetic regulation to attenuate let-7 expression in Helicobacter pylorirelated carcinogenesis. Gut. 2012;62(11):1536-46.

27. Herr I, Buchler MW. Dietary constituents of broccoli and other cruciferous vegetables: implications for prevention and therapy of cancer. Cancer Treat Rev. 2010:36(5):377-83.

28. Hesson LB. Gut microbiota and obesity-related gastrointestinal cancer: a focus on epigenetics. Trans Gastrointest Cancer. 2013;2(4):204-10.

29. Heuck CJ, Mehta J, Bhagat T, Gundabolu K, Yu Y, Khan S. Myeloma is characterized by stage- specific alterations in DNA methylation that occur early during myelomagenesis. J Immunol. 2013;190(6):2966-75.

30. Hooper LV, Midtvedt T, Gordon J. How host-microbial interactions shape the nutrient environment of the mammalian intestine. Annu Rev Nutr. 2002;22(1):283-307.

31. Hu G, Gong AY, Roth AL, Huang BQ, Ward HD, Zhu G. Release of luminal exosomes contributes to TLR4-mediated epithelial antimicrobial defense. PLoS Pathog. 2013;9(4), e1003261.

32. Hu S, Dong TS, Dalai SR, Wu F, Bissonette M, Kwon JH. The microbe-derived short chain fatty acid butyrate targets miRNA-dependent p21 gene expression in human colon cancer. PLoS One. 2011;6(1), e16221.

33. Hughes R, Cross AJ, Pollock JRA, Bingham S. Dose-dependent effect of dietary meat on endogenous colonic N-nitrosation. Carcinogenesis. 2001;22(1):199-202.

34. Hullar MA, Fu BC. Diet, the gut microbiome, and epigenetics. Cancer J (Sudbury, Mass). 2014;20(3):170.

35. Hýzd'alova M, Hofmanova J, Pachermk J, Vaculova A, Kozubik A. The interaction of butyrate with TNF-a during differentiation and apoptosis of colon epithelial cells: role of NF-k B activation. Cytokine. 2008;44(1):33-43.

36. Jeffery IB, O'Toole PW. Diet-microbiota interactions and their implications for healthy living. Nutrients. 2013;5(1):234-52.

37. Ju YH, Fultz J, Allred KF, Doerge DR, Helferich WG. Effects of dietary daidzein and its metabolite, equol, at physiological concentrations on the growth of estrogen-dependent human breast cancer (MCF-7) tumors implanted in ovariectomized athymic mice. Carcinogenesis. 2006;27(4):856-63.

38. Kala R, Peek GW, Hardy TM, Tollefsbol TO. MicroRNAs: an emerging science in cancer epigenetics. J Clinical Bioinformatics. 2013;3:6.

39. Koeth RA, Wang Z, Levison BS, Buffa JA, Org E, Sheehy BT. Intestinal microbiota metabolism of Icarnitine, a nutrient in red meat, promotes atherosclerosis. Nat Med. 2013;19(5):576-85.

40. Kondo Y. Epigenetic cross-talk between DNA methylation and histone modifications in human cancers. Yonsei Med J. 2009;50(4):455-63.

41. Kuitunen M, Saukkonen T, Ilonen J, Åkerblom HK, Savilahti E. Intestinal permeability to mannitol and lactulose in children with type 1 diabetes with the HLA-DQB1* 02 allele. Autoimmunity. 2002;35(5):365-8.

42. Kumar H, Lund R, Laiho A, Lundelin K, Ley RE, Isolauri E. Gut microbiota as an epigenetic regulator: pilot study based on whole-genome methylation analysis. MBio. 2014;5(6):e02113-4.

43. Legette LL, Prasain J, King J, Arabshahi A, Barnes S, Weaver CM. Pharmacokinetics of equol, a soy isoflavone metabolite, changes with the form of equol (dietary versus intestinal production) in ovariectomized rats. J Agric Food Chem. 2014;62(6):1294-300.

44. Ley RE, Bäckhed F, Turnbaugh PJ, Lozupone CA, Knight RD, Gordon الر. Obesity alters gut microbial ecology. Proc Natl Acad Sci U S A. 2005;102(31):11070-5.

45. Ley RE, Knight R, Gordon Jl. The human microbiome: eliminating the biomedical/environmental dichotomy in microbial ecology. Environ Microbiol. 2007:9(1):3-4.

46. Li G, Su H, Zhou Z, Yao W. Identification of the porcine G protein-coupled receptor 41 and 43 genes and their expression pattern in different tissues and development stages. 2014.

47. Logan AC, Rao AV, Irani D. Chronic fatigue syndrome: lactic acid bacteria may be of therapeutic value. Med Hypotheses. 2003;60(6):915-23.

48. Loscalzo J. Lipid metabolism by gut microbes and atherosclerosis. Circ Res. 2011;109(2):127-9.

49. Louis P, Flint HJ. Diversity, metabolism and microbial ecology of butyrateproducing bacteria from the human large intestine. FEMS Microbiol Lett. 2009;294(1):1-8.

50. Mageroy MH, Tieman DM, Floystad A, Taylor MG, Klee HJ. A Solanum lycopersicum catechol-O-methyltransferase involved in synthesis of the flavor molecule guaiacol. Plant J. 2012;69(6):1043-51.

51. Maia BM, Rocha RM, Calin GA. Clinical significance of the interaction between non-coding RNAs and the epigenetics machinery: challenges and opportunities in oncology. Epigenetics. 2014;9(1):75-80.

52. Mallegol J, Niel GV, Heyman M. Phenotypic and functional characterization of intestinal epithelial exosomes. Blood Cell Mol Dis. 2005;35(1):11-6.

53. Martinez-Medina M, Aldeguer X, Gonzalez-Huix F, Acero D, Garcia-Gil LJ. Abnormal microbiota composition in the ileocolonic mucosa of Crohn's disease patients as revealed by polymerase chain reaction-denaturing gradient gel electrophoresis. Inflamm Bowel Dis. 2006;12(12):1136-45.

54. Maslowski KM, Vieira AT, Ng A, Kranich J, Sierro F, Yu D. Regulation of inflammatory responses by gut microbiota and chemoattractant receptor GPR43. Nature. 2009;461(7268):1282-6.

55. Matarese F, Pau ECS, Stunnenberg HG. 5-Hydroxymethylcytosine: a new kid on the epigenetic block? Mol Syst Biol. 2011;7(1):562.

56. McGarr SE, Ridlon JM, Hylemon PB. Diet, anaerobic bacterial metabolism, and colon cancer: a review of the literature. J Clin Gastroenterol. 2005;39(2):98-109.

57. Meeran SM, Patel SN, Tollefsbol TO. Sulforaphane causes epigenetic repression of hTERT expression in human breast cancer cell lines. PLOS One. 2010;5(7), e11457.

58. Menendez JA, Corominas-Faja B, Cuyàs E, Alarcón T. Metabostemness: metaboloepigenetic reprogramming of cancer stem-cell functions. Oncoscience. 2014;1(12):803.

59. Mercer TR, Dinger ME, Mattick JS. Long non-coding RNAs: insights into functions. Nat Rev Genet. 2009;10(3):155-9.

60. Mudbhary R, Sadler KC. Epigenetics, development, and cancer: zebrafish make their mark. Birth Defects Research Part C: Embryo Today: Reviews. 2011;93(2):194-203.

61. Navarro SL, Li F, Lampe JW. Mechanisms of action of isothiocyanates in cancer chemoprevention: an update. Food Function. 2011;2(10):579-87.

62. Nör C, Sassi FA, Farias CB, Schwartsmann G, Abujamra AL, Lenz G. The histone deacetylase inhibitor sodium butyrate promotes cell death and differentiation and reduces neurosphere formation in human medulloblastoma cells. Mol Neurobiol. 2013;48(3):533-43.

63. Ohigashi S, Sudo K, Kobayashi D, Takahashi O, Takahashi T, Asahara T. Changes of the intestinal microbiota, short chain fatty acids, and fecal pH in patients with colorectal cancer. Dig Dis Sci. 2013;58(6):1717-26.

64. Parracho HM, Bingham MO, Gibson GR, McCartney AL. Differences between the gut microflora of children with autistic spectrum disorders and that of healthy children. J Med Microbiol. 2005;54(10):987-91.

65. Pastor WA, Aravind L, Rao A. TETonic shift: biological roles of TET proteins in DNA demethylation and transcription. Nat Rev Mol Cell Biol. 2013;14(6):34156.

66. Penders J, Thijs C, Vink C, Stelma FF, Snijders B, Kummeling I. Factors influencing the composition of the intestinal microbiota in early infancy. Pediatrics. 2006;118(2):511-21.

67. Peserico A, Simone C. Physical and functional HAT/HDAC interplay regulates protein acetylation balance. BioMed Res Int. 2010;2011:371832.

68. Plottel CS, Blaser MJ. Microbiome and malignancy. Cell Host Microbe. 2011;10(4):324-35. 
69. Pompei A, Cordisco L, Amaretti A, Zanoni S, Matteuzzi D, Rossi M. Folate production by bifidobacteria as a potential probiotic property. Appl Environ Microbiol. 2007;73(1):179-85.

70. Rajilić-Stojanović M, Biagi E, Heilig HG, Kajander K, Kekkonen RA, Tims S. Global and deep molecular analysis of microbiota signatures in fecal samples from patients with irritable bowel syndrome. Gastroenterology. 2011;141(5):1792-801.

71. Rea IM, Dellet M, Mills Kl. Living long and ageing well: is epigenomics the missing link between nature and nurture? Biogerontology. 2015;1-22. doi: 10.1007/s10522-015-9589-5.

72. Rodríguez LG, Ruigómez A, Wallander M-A, Johansson S, Olbe L. Detection of colorectal tumor and inflammatory bowel disease during follow-up of patients with initial diagnosis of irritable bowel syndrome. Scand J Gastroenterol. 2000;35(3):306-11.

73. Roth SY, Denu JM, Allis CD. Histone acetyltransferases. Annu Rev Biochem. 2001;70(1):81-120.

74. Rowland IR, Wiseman $H$, Sanders TA, Adlercreutz $H$, Bowey EA. Interindividual variation in metabolism of soy isoflavones and lignans: influence of habitual diet on equol production by the gut microflora. Nutr Cancer. 2000;36(1):27-32

75. Saldanha SN, Kala R, Tollefsbol TO. Molecular mechanisms for inhibition of colon cancer cells by combined epigenetic-modulating epigallocatechin gallate and sodium butyrate. Exp Cell Res. 2014;324(1):40-53.

76. Samsel A, Seneff S. Glyphosate's suppression of cytochrome P450 enzymes and amino acid biosynthesis by the gut microbiome: Pathways to modern diseases. Entropy. 2013;15(4):1416-63.

77. Selkrig J, Wong P, Zhang X, Pettersson S. Metabolic tinkering by the gut microbiome: implications for brain development and function. Gut Microbes. 2014:5(3):369-80.

78. Shenderov BA. Gut indigenous microbiota and epigenetics. Microbial Ecol Health Dis. 2012;23.

79. Shenderov BA. Metabiotics: novel idea or natural development of probiotic conception. Microbial Ecol Health Dis. 24

80. Shenderov BA, Midtvedt T. Epigenomic programming: a future way to health? Microbial Ecol Health Dis. 2014;25.

81. Shimizu K, Muranaka Y, Fujimura R, Ishida H, Tazume S, Shimamura T. Normalization of reproductive function in germfree mice following bacterial contamination. Exp Anim. 1998:47(3):151-8.

82. Shin Jl, Brusselle GG. Mechanistic links between COPD and lung cancer: a role of microRNA let-7? Nat Rev Cancer. 2014;14(1):70.

83. Smythies LE, Smythies JR. Exosomes in the gut. Front Immunol. 2014;5:104.

84. Stringer AM, Gibson RJ, Bowen JM, Keefe DM. Chemotherapy-induced modifications to gastrointestinal microflora: evidence and implications of change. Curr Drug Metab. 2009;10(1):79-83.

85. Taberlay PC, Jones PA. DNA methylation and cancer. Prog Drug Res. 2011;67:1-23.

86. Takahashi K. Influence of bacteria on epigenetic gene control. Cell Mol Life Sci. 2014:71(6):1045-54

87. Takahashi K, Sugi Y, Nakano K, Tsuda M, Kurihara K, Hosono A. Epigenetic control of the host gene by commensal bacteria in large intestinal epithelial cells. J Biol Chem. 2011;286(41):35755-62.

88. Tsuji S, Kawai N, Tsujii M, Kawano S, Hori M. Review article: inflammationrelated promotion of gastrointestinal carcinogenesis - a perigenetic pathway. Aliment Pharmacol Ther. 2003;18(s1):82-9.

89. Turnbaugh PJ, Ridaura VK, Faith JJ, Rey FE, Knight R, Gordon JI. The effect of diet on the human gut microbiome: a metagenomic analysis in humanized gnotobiotic mice. Sci Transl Med. 2009;1(6):6ra14

90. Vaahtovuo J, Munukka E, Korkeamaki M, Luukkainen R, Toivanen P. Fecal microbiota in early rheumatoid arthritis. J Rheumatol. 2008;35(8):1500-5.

91. Versalovic J. Highlander SK. The human microbiome: Petrosino JF; 2015.

92. Vieira AT, Macia L, Galvão I, Martins FS, Canesso MC, Amaral FA. A role for gut microbiota and the metabolite-sensing receptor GPR43 in a murine model of gout. Arthritis Rheumatol. 2015;67(6):1646-56.

93. Vieira SM, Pagovich OE, Kriegel MA. Diet, microbiota and autoimmune diseases. Lupus. 2014;23(6):518-26.

94. Walker AW, Dunkan SH, Leitch EC, Child MW, Flint HJ. pH and peptide supply can radically alter bacterial populations and short-chain fatty acid ratios within microbial communities from the human colon. Appl Environ Microbiol. 2005;71(7):3692-700.
95. Weir TL, Manter DK, Sheflin AM, Barnett BA, Heuberger AL, Ryan EP. Stoo microbiome and metabolome differences between colorectal cancer patients and healthy adults. PLoS One. 2013;8(8), e70803.

96. Wollowski I, Rechkemmer G, Pool-Zobel BL. Protective role of probiotics and prebiotics in colon cancer. Am J Clin Nutr. 2001;73(2):451s.

97. Wu X, Kassie F, Mersch-Sundermann V. Induction of apoptosis in tumor cells by naturally occurring sulfur-containing compounds. Mutation Res/Reviews Mutation Res. 2005:589(2):81-102.

98. Yao H, Rahman I. Current concepts on the role of inflammation in COPD and lung cancer. Curr Opin Pharmacol. 2009;9(4):375-83.

99. Zgouras D, Wächtershäuser A, Frings D, Stein J. Butyrate impairs intestinal tumor cell-induced angiogenesis by inhibiting HIF-1a nuclear translocation. Biochem Biophys Res Commun. 2003:300(4):832-8.

100. Zhang W, Lu H, Graham DY. An update on Helicobacter pylori as the cause of gastric cancer. Gastrointestinal Tumors. 2014;1(3):155-65.

\section{Submit your next manuscript to BioMed Central and take full advantage of:}

- Convenient online submission

- Thorough peer review

- No space constraints or color figure charges

- Immediate publication on acceptance

- Inclusion in PubMed, CAS, Scopus and Google Scholar

- Research which is freely available for redistribution 